\title{
Modelling and (adaptive) control of greenhouse climates
}

\author{
A. J. Udink ten Cate (Department of Physics and Meteorology, Agricultural Uni- \\ versity, Wageningen, Netherlands)
}

Accepted: 7 May 1984

\begin{abstract}
After a discussion on control of greenhouse climates, new algorithms for temperature control are presented and tested in practice. A novel approach of modelling of the climate control process is presented by using time-series analysis techniques.

Key-words: greenhouse climates, climate control, identification, temperature control, adaptive control.
\end{abstract}

System concepts. There is some ambiguity with respect to what exactly control in greenhouses is, since in practical horticulture control procedures are used. Therefore, the term GCFC (Greenhouse Climate Feedback/Feedforward Control) is introduced, where 'control' has a strict meaning. It is ascertained that - despite much research on control procedures - in the field of GCFC few results have been reported in the literature.

The existing control methods for greenhouse climates can be described with the concept of a hierarchical system formulation. The problem of creating a beneficial environment for the crop can be described as a system with three levels. On the first level GCFC is found, on the second plant growth on a diurnal basis, and on the third level crop growth and development. Control procedures as they are employed in the practice of horticulture can be seen as a combination of the levels 1 and 2 , whereas GCFC restricts itself to level 1. It is suggested that the control procedures can be improved by solving the GCFC problem adequately and by formulating the procedures as setpoint control of level one.

The idea of the hierarchical system can be employed to describe the optimal control of crop growth. The system is broken down into less complex sub-systems (levels in the hierarchical system) and each of the higher levels is optimized in terms of output variables of the lower levels. This assumes that the variables used in the optimization correspond with the relevant level.

Modelling. A new apporach to the modelling dynamic greenhouse climate processes can be formulated by using an approach which incorporates a sequence of key features which differ from the usual one.

The first is that the greenhouse climate process - in our case restricted to temperature - and the actuator processes (mixing valve process and ventilation window process) are described separately. By this way of description the main non-linearities are removed from the climate process. 
The following steps follow logically when dynamic systems are of interest: the climate (temperature) process is formulated in terms of incremental variables and a working point is defined. Essential in greenhouses is that the working point is slowly time-varying. By supplying (relatively) high-frequency signals as inputs of the system, the low-frequency variations of the working point can be rejected by using filter techniques. Parameter estimation is carried out in the time domain, with optimization techniques in order to determine the parameters of a simple model. The experiments are carried out concurrently in identical compartments for various working points.

Up to this point, the traditional goal of control engineering is satisfied, since the process is sufficiently described. However, from the results some dependencies on physical phenomena could be guessed. Therefore it is tried to interprete the results in terms of physical parameters. Because a detailed physical model does not comply with the simple dynamic model, an approach is followed with heating-load coefficients ( $k$ values), where the heating-load coefficients enter as parameters into a simple thermal model.

To carry out the interpretation at least one heating-load parameter has to be known. For this the parameter describing the heat flow from the heating pipe network into the greenhouse is used. This parameter is determined from one type of experiment, and is found to be non-linear. Because the parameter estimation of the dynamic models is carried out on various temperature levels, the non-linearity of the heating system can be checked and is found to comply in both types of experiments.

From the parameter of the heating system, the other parameters can be calculated. The values are consistent, as they are confirmed in several experiments under various outside weather conditions. The value of the heating system parameter is found to agree with values from literature. However, the values found from parameter estimation differ roughly by a factor two from the corresponding values found in the literature.

This latter result could be caused by a wrong value of the heating system parameter. Therefore, a steady-state analysis is carried out to determine the parameters, where again the heating system parameter is assumed to be known. In this case the parameters agree with results found in the literature, so it may be concluded that the parameters of the dynamic (control) models and the static heating-load models differ, and that they are frequency-dependent. For a few cases it is also demonstrated that it is possible to model the slowly time-varying working point with a quasi-static model.

Control. When the behaviour of the control loop is analysed, in GCFC the performance is mainly determined by saturations due to the outside weather conditions. This differs from the normal pattern in control and leads to the formulation of GCFC performance criteria in terms of overshoot, sag and undershoot.

A new dog-lead PI algorithm is designed to give a better response in situations where the controls are saturated. In a field trial from 28 January to 24 March 1981 - carried out at the Glasshouse Crops and Experiment Station (Naaldwijk, Ne- 
therlands) - it was demonstrated that the dog-lead algorithm is by far superior in performance with respect to undershoot, better with respect to sag, and similar with respect to overshoot. Since undershoot is the most severe problem with respect to poor performance, it is suggested that the dog-lead algorithm is of great practical interest.

In greenhouses with a lower and an upper heating pipe network, the temperature can be controlled adequately by using a split-range algorithm.

Adaptive control. Because in a greenhouse the GCFC characteristics are varying, adaptive control can be employed in order to improve the controller behaviour. For the glasshouse used in the above field trial, an adaptive algorithm was designed where the parameter estimation was based on a gradient procedure with asymptotic convergence of the parameter error. Results of the field test - which concludes several years of experience with this adaptive method - indicate clearly that adaptation does not bring a significant improvement.

This paper is based on a doctoral thesis, Agricultural University, Wageningen, 1983. xii +159 pp., 53 figs., 15 tables, 135 refs. English, Dutch summary. One chapter has been published as a paper in International Journal of Control.

Available as paper copy (order R006P, $f 30$ including postage) or microfiches (order R006M, $f$ 17,50 including postage) at: NARD, clo Pudoc, P.O. Box 4, 6700 AA Wageningen, Netherlands (telex 45015 blhwg nl).

\title{
Effects of wider initial spacing of teak (Tectona grandis) on income and income distribution in the taungya system in Java
}

Peter van der Hout (Department of Forest Management, Agricultural University, Generaal Foulkesweg 64, Wageningen, Netherlands)

Accepted: 10 April 1984

\begin{abstract}
Food production, net farm income and net present value increased considerably with a change in initial spacing of teak from $3 \mathrm{~m} \times 1 \mathrm{~m}$ as in the traditional taungya system in Java to $6 \mathrm{~m} \times 1 \mathrm{~m}$. Teak production and financial returns to the State Forest Enterprise decreased only slightly.

Key-words: taungya, teak (Tectona grandis), spacing, financial return, agroforestry, leucaena (Leucaena leucocephala).
\end{abstract}

